\title{
2030 Target for Energy Efficiency and Emission Reduction in the EU Paper Industry
}

\author{
Shuangjie $\mathrm{Li}^{1}, \mathrm{Li} \mathrm{Li}^{1}$ and Liming Wang ${ }^{1,2, *}$ \\ 1 School of Economics and Management, Beijing University of Technology, Beijing 100024, China; \\ lishuangjie@emails.bjut.edu.cn (S.L.); lili@emails.bjut.edu.cn (L.L.) \\ 2 Irish Institute for Chinese Studies, University College Dublin, D04 V1W8 Dublin, Ireland \\ * Correspondence: liming.wang@ucd.ie
}

\section{check for}

updates

Citation: Li, S.; Li, L.; Wang, L. 2030 Target for Energy Efficiency and Emission Reduction in the EU Paper Industry. Energies 2021, 14, 40.

https://dx.doi.org/10.3390/ en14010040

Received: 7 November 2020 Accepted: 18 December 2020 Published: 23 December 2020

Publisher's Note: MDPI stays neutral with regard to jurisdictional claims in published maps and institutional affiliations.

Copyright: () 2020 by the authors. Licensee MDPI, Basel, Switzerland. This article is an open access article distributed under the terms and conditions of the Creative Commons Attribution (CC BY) license (https: / / creativecommons.org/ licenses/by/4.0/).

\begin{abstract}
Improving energy efficiency is an effective way to address the issues of economic development, energy saving and emissions reduction. For any important industries it is therefore necessary to measure energy efficiency and set a practical target for it. In this paper, we use CCR, SBM and energy intensity to measure the energy efficiency of the paper industries of $22 \mathrm{EU}$ countries. Results indicate that the SBM and CCR efficiency value is more meaningful for policy makers than that of energy intensity, as measurement results of energy intensity deviate from reality and economic efficiency. The CCR and SBM have roughly the same fluctuation trends and the average SBM energy efficiency value is 0.71 , always 10 percent lower than CCR model, as it takes simultaneous account of both the optimal input-output and has more discriminatory power in efficiency measurement. Furthermore, EU policy makers could improve energy efficiency by raising energy prices. As for the 2030 EU target of energy saving and emission reduction, the EU should pay more attention to five major paper producers: Finland, Sweden, Germany, the United Kingdom and Italy.
\end{abstract}

Keywords: TFEE; EU paper industry; SBM; energy saving; emission reduction; 2030 target

\section{Introduction}

According to the BP Statistical Review of World Energy, primary energy consumption grew at a rate of $2.9 \%$ in 2018 , almost double its 10 -year average of $1.5 \%$ per year and the fastest since 2010. Specifically, in 2018 the primary energy consumption worldwide was $13,864.9$ million tonnes of oil equivalent (Mtoe). At the same time, carbon emissions rose at a rate of $2.0 \%$, the highest rate for seven years, reaching 33,890.8 million tonnes in 2018, as a result of increased energy consumption, moving even further away from the accelerated transition envisaged by the Paris Climate Goals [1].

In BP's 2019 economic analysis report, they estimate that energy consumption growth can be traced back to weather-related impacts, as households and businesses have increased demand for cooling and heating to cope with unusually hot and cold weather. That is to say, the increase in extreme weather leads to an increase in energy consumption, which in turn leads to an increase in carbon emissions. Greenhouse gas emissions are the cause of extreme weather. It is worth paying attention to a vicious circle among the three, i.e., the cyclical relationship among energy consumption, greenhouse gas emissions and extreme weather. The world is on an unsustainable path: the longer carbon emissions continue to grow, the more difficult and costly it will be to adjust to net zero carbon emissions [1].

Obviously, excessive energy consumption has caused great damage to the environment and the climate, and energy use is a major source of greenhouse gas emission [2,3]. On the other hand, it is hard to reduce energy consumption considering the increase in energy demand due to the development of the world economy. In this context, improving energy efficiency has become a widely recognized way to achieve the SDGs, because it can address economic development, energy saving and environmental issues simultaneously. 
As an essential production factor, energy plays an important role in many sectors. The key sectors for tracking energy use are transport, services, manufacturing and the residential sector. Among them, the paper industry is considered one of the most energyintensive subsectors in the manufacturing sector [4].

In this paper, we investigate the European Union (EU) paper industry as a subsector of energy consumption. According to the Confederation of European Paper Industries (CEPI), in terms of total paper production around the world, Asian, North America, and European paper outputs account for $40 \%, 20 \%$ and $25 \%$ of the world's total, respectively [5]. Within the EU, the energy consumption of the paper industry in EU countries accounted for $14.77 \%$ of the total manufacturing consumption in 2017. Therefore, improving the energy efficiency in the paper industries in EU countries is of great significance to European energy saving and emission reduction goals.

The EU paper industry has been working hard to improve its energy efficiency and reduce emissions with notable results in recent years. The most prominent policies to reduce emissions in the EU include the Emission Trading System (ETS) and the 2012 Bioeconomy Strategy. The purpose of these policies is to ensure fossil materials to be replaced by sustainable alternatives, which is reflected in the EU Horizon 2020 research framework programme. This has already achieved a $27 \%$ reduction in carbon emissions from 2005 to date, which is believed far from enough [5]. Also, the EU has developed specific policies to achieve sustainable development, including 2030 environmental, energy and climate targets, which were adopted by the European Council in October 2014 and then revised upwards in 2018.

Specifically, the 2030 climate and energy framework includes EU-wide targets and policy objectives for the period 2021 to 2030 [6]. Key targets for 2030 are:

- At least 40\% cuts in greenhouse gas emissions (from 1990 levels)

- At least 32\% share for renewable energy

- At least $32.5 \%$ improvement in energy efficiency.

In this paper, CCR and SBM models are employed to measure the total factor energy efficiency (TFEE) of the paper industries in $22 \mathrm{EU}$ countries. This is followed by a comparative analysis of the results as well as energy intensity. To the best of our knowledge, there are only two papers published to date in the area of energy efficiency for the paper industry in Europe, both of which focused on papermaking enterprises in Sweden and Germany. Therefore, this study fills the gap in this field by examining energy efficiency of the paper industry in $22 \mathrm{EU}$ countries and presents policy implications for EU decision makers. In addition, a more complete set of input-output indicators has been employed in this paper to measure total factor energy efficiency. It is believed that the measuring results in this paper are more reliable and accurate. Empirical results indicate that the EU paper industry has great potentials for energy saving and emission reduction of $33 \%$ and $71 \%$ per year respectively, which is much higher than the 2030 energy saving target of the EU. Therefore, the EU paper industry has potential to achieve its 2030 target.

\section{Literature Review}

In view of the important role of energy efficiency in economic development, some in-depth research on energy efficiency has been conducted by scholars in recent years. At present, the measurements of energy efficiency can be roughly divided into two categories: Single Factor Energy Efficiency (SFEE) and Total Factor Energy Efficiency (TFEE).

\subsection{SFEE}

\subsubsection{Energy Intensity $(\mathrm{EI}=\mathrm{E} / \mathrm{GDP})$}

Energy intensity, also known as energy consumption per unit of output, is the commonly used indicator of SFEE and refers to the amount of energy consumed per unit of output of a country or industries over a given period of time. At the national level, energy intensity is the ratio of total domestic primary energy consumption or final energy consumption to gross domestic product. This index is easy to calculate and convenient for 
comparative analysis among different subjects. Therefore, it is widely used by scholars and government departments as a key indicator for macro-economic policies.

\subsubsection{Energy Productivity $(E P=G D P / E)$}

Energy productivity is the reciprocal of energy intensity, which refers to how much economic output can be produced per unit of energy consumption.

Energy efficiency is to produce the same number of services or useful outputs with less energy. SFEE only measures the proportional relationship between energy input and gross value added and there has been widespread criticism of using energy intensity for measuring energy efficiency [7]. Energy alone cannot produce any outputs. Energy must be combined with other inputs to produce outputs [8]. The main problem with energy/GDP, as pointed out by Wilson et al. [9], is that it does not measure the underlying technical energy efficiency, which can be misleading. As SFEE measurements, both energy intensity and energy productivity only take energy into account, and ignore capital, labor and other inputs. At the country or region level, some industries have alternatives among a variety of inputs. With more capital, labor and other inputs, the energy input can be reduced, thereby improving energy productivity, but this doesn't mean an improvement in energy efficiency or economic efficiency for the regions or the industries.

\subsection{TFEE}

Energy efficiency improvement relies on total-factor productivity improvement [10]. Unlike SFEE, which only considers a single input variable and a single output variable, the TFEE indicator is calculated under the framework of a variety of input and output variables, fully considering the results of interaction of various factors in production activities and thus overcoming the deficiency of the SFEE method to a certain extent. The dominant idea of TFEE is to minimize input when output remains unchanged or maximize output when input remains unchanged. As for the measurement of energy efficiency, TFEE is the ratio between the optimal energy input and the actual energy input, and it is a relative efficiency index. The TFEE index was first proposed by $\mathrm{Hu}$ and Wang [8]. Since then, it has been widely developed and applied. According to development of the total factor framework, it is roughly divided into three stages.

The first stage is a total factor framework without undesirable outputs. $\mathrm{Hu}$ and Wang [8] take actual output as the only variable without taking the impact on the environment into account. Taking capital, labor and energy consumption as input variables and real GDP as output variables, Hu and Kao [11] use a DEA model to measure the energy-saving targets of 17 APEC economies and find that the average value in 2000 was $13.70 \%$. Zhao et al. [12] used capital, labor, energy consumption and industrial added value for each sector in 10 provinces from eastern, central and western regions of China to investigate TFEE change at provincial sector level during the period 1997-2007. The results in that study indicate that over the time, TFEE of each sector has improved in general. In addition, Honma and Hu [13] measured the TFEE of 47 regions in Japan for the period 1993-2003; Zhang et al. [14] explored total-factor energy efficiency and change trends in 23 developing countries by applying DEA window analysis. Many other scholars like Mousavi-Avval et al. [15], Blomberg et al. [16] and Song et al. [17,18] also employed the same total-factor framework to measure energy efficiency.

The second stage is an ecological total factor framework. On the basis of the first stage, it considers the impact of production on the environment, and treats the emission of production as the undesired output. It conforms to the actual production process as well as to the concept of sustainable development. Therefore, it is an improvement and development from the total factor framework in the first stage. Zhou and Ang [19] and Yeh et al. [20] take account of desirable outputs together with undesirable outputs in their models; Li and Hu [21] also computed the ecological TFEE of 30 regions in China for the period 2005-2009 using a slack-based model. The ecological TFEE is constructed as the ratio of the target energy input suggested from the SBM model with undesirable outputs 
of the actual energy input in a region. Özkara et al. [22] investigated the total-factor energy efficiency scores of manufacturing industries in 26 regions in Turkey between the years 2003 and 2012, using four DEA models supported by a total-factor framework taking $\mathrm{CO}_{2}$ emission as undesirable output. Emrouznejad and Yang [23] used a novel MalmquistLuenberger productivity index based on directional distance function to address the relative efficiency and productivity of a group of homogenous DMUs as well as to evaluate $\mathrm{CO}_{2}$ emissions reduction in Chinese light manufacturing industries. Undesirable outputs are also used by Camioto et al. [24]; Choi et al. [25]; Liu and Lin [26,27]; Perez et al. [28]; Sahoo et al. [29] in their studies.

Most of the papers related to TFEE, reviewed above, follow the framework proposed by $\mathrm{Hu}$ and Wang [8] and $\mathrm{Li}$ and $\mathrm{Hu}$ [21], i.e., capital, labor and energy consumption are taken as input variables, added value is taken as a desirable output, with or without emissions as undesirable outputs. Following the principle that the input indicators should be consistent with the output indicators, $\mathrm{Li}$ and $\mathrm{Li}$ [30] propose a revised input-output framework of TFEE in which the output indicator corresponding to capital, labor, energy consumption and other intermediate inputs is gross output rather than the value added output. Therefore, the total factor framework for measuring energy efficiency should take gross output as the desirable output. In their study, undesirable output is composed of waste residue, emission and waste water. This recently developed framework could be classified as the third stage of TFEE with different input-output indicators.

\section{Method and Data}

The data envelopment analysis (DEA) method proposed by Charnes, Cooper and Rhodes (CCR) [31] in 1978 to calculate TFEE is employed in this study. DEA is a method for evaluating the relative efficiency of several decision-making units (DMUs) with the same type of inputs and outputs, and does not require the form of a production function to be set in advance. This method is based on sample input-output data and aims to find a piecewise linear production frontier. By calculating the distance between the actual production point and the production frontier of all DMUs, the efficiency of each DMU is measured. This method is used to measure the TFEE for the paper industries in EU countries. The CCR model is one of the basic DEA models. With the development of modeling, a variety of DEA models have emerged, including the SBM model.

\subsection{CCR and SBM Model Revision of Indicator Framework}

The CCR model assumes that the return to scale is constant, that is, all DMUs have the same optimal scale frontier. Let's say there are I DMU, and each DMU has N inputs and M outputs. The input and output of the ith DMU are expressed by the column vectors xi and qi respectively. The $\mathrm{N} \times \mathrm{I}$ input matrix $X$ and $\mathrm{M} \times \mathrm{I}$ output matrix $\mathrm{Q}$ represent all the data of the ith DMU. Then the input-oriented CCR model with constant return to scale is:

$$
\begin{gathered}
\operatorname{Min}_{\theta, \lambda} \theta \\
\text { st }-\mathrm{q}_{i}+\mathrm{Q} \lambda \geq 0 \\
\theta_{x i}-\mathrm{X} \lambda \geq 0 \\
\lambda \geq 0
\end{gathered}
$$

In this model, production technology is defined as $\mathrm{T}=\{(x, \mathrm{q}): \mathrm{q} \leq \mathrm{Q} \lambda, x \geq \mathrm{X} \lambda\}$; $\lambda$ represents a constant vector. $\theta$ represents the efficiency value of the $i$-th DMU, which satisfies that $\theta \leq 1$. When $\theta$ is equal to 1 , it indicates that this DMU is on the frontier and is technically effective. Otherwise, it is technically ineffective.

The traditional DEA model is basically radial. The influence of slack variables on energy efficiency cannot be measured, so the efficiency value of the DMUs may be overestimated. Radial measure of efficiency only considers proportional reduction of inputs and hence it lacks discriminatory power and is not able to provide a comprehensive measure of efficiency [30]. While radial-based models can only deal with a reduction in the proportion 
of inputs and outputs, when there is a non-zero slack of inputs and outputs, such models will overestimate the efficiency of DMUs. Therefore, there will be a certain deviation between the calculated efficiency and the actual efficiency.

To this end, Tone [32] proposed SBM models to solve this problem. The SBM model directly incorporates slack variables into the objective function, which solves the problem of slack. On the other hand, the SBM model is a non-radial measurement method in the DEA model, thereby avoiding the deviation in energy efficiency measurement caused by radial. Therefore, the SBM model can better reflect the essence of efficiency than other models. The following is the SBM model, where $\rho$ represents the technical efficiency:

$$
\begin{gathered}
\min \rho=\frac{1-\left(\frac{1}{m}\right) \sum_{i=1}^{m} \frac{s_{i}^{-}}{x_{i 0}}}{1+\left(\frac{1}{s}\right) \sum_{r=1}^{s} \frac{s_{r}^{+}}{y_{r 0}}} \\
\text { st } x_{0}=\mathrm{X} \lambda+s^{-} \\
y_{0}=\mathrm{Y} \lambda-s^{+} \\
\sum_{\mathrm{j}=1}^{\mathrm{n}} \lambda_{\mathrm{j}}=1 \\
\lambda \geq 0, s^{-} \geq 0, s^{+} \geq 0
\end{gathered}
$$

$x_{0}$ and $y_{0}$ are the input vector and output vector of a certain DMU respectively; $s_{i}^{-}$is the slack value of $i$-th input, and $s_{r}^{+}$is the slack value of $r$-th output.

According to $\mathrm{Hu}$ and Wang's [8] definition of TFEE, the calculation formula is as follows:

$$
\text { TFEE }=\frac{\text { Target energy consumption }}{\text { Actual energy consumption }}
$$

Target energy consumption is equal to actual energy consumption minus energy adjustment amount. In the CCR model, energy adjustment amount includes proportional reductions in energy consumption and energy-related slack. In the SBM model, the energy adjustment amount is the total energy slack. The calculated energy adjustment amount is an invalid part of the actual energy consumption and it is also the amount of potential energy savings while keeping existing output constant. The greater the adjustment of energy input, the lower the energy efficiency of the DMU, i.e., more energy input can be saved. If the adjustment of energy input is 0 , that is, target energy consumption is equal to the actual energy consumption, indicating that the DMU is located on the frontier and is efficient.

\subsection{Data Revision of Indicator Framework}

In the existing literature on TFEE, there is duplication or omission in the selected input-output indicators, which do not conform to the theory of production economics and actual production practice. The most commonly used input-output indicators are capital, labor and energy as inputs and added value as an output indicator. Some scholars consider the impact of production on the environment and added undesirable output to the output indicator, while some scholars consider other intermediate inputs, but most of the existing literature fails to avoid duplication and omission of indicators. The main problems are as follows:

(1) Other intermediate inputs are not often included as input indicators. The sum of energy consumption and other intermediate input is an intermediate input in production. Because inputs such as capital, labor and energy alone cannot complete overall production and create output. Therefore, other intermediate input is indispensable.

(2) The desired output should be gross output, not added value (both GDP and industrial value-added are added value). According to economic theory, the transferred and newly created value of capital and labor input after participating in production constitute added value. Value added does not consider the use of intermediate consumption (the sum of energy consumption and other intermediate inputs), and 
only relates to capital and labor. Therefore, in order to ensure the consistency of the accounting scope and value composition in the production process, that is, to keep the input and output indicators consistent, if the output is added value, the corresponding input indicators should use capital and labor, but not energy. Gross output is the sum of value of all goods and services produced by the production sector in a given period of time, including both added value and intermediate consumption. As shown in formula (4), GVA represents gross value added, which is roughly equal to GDP and can be expressed as the difference between gross output and intermediate consumption. In the process of national economic accounting, value added (GDP) should be used to avoid double counting if it is used for distribution purposes. If it is used for production purposes, however, gross output (GO) should be used. Although there is a problem of double counting in most cases, it will not affect the results much in the efficiency analysis here; otherwise, replacing GO with added value (GDP) will underestimate the production scale by more than $50 \%$, thus resulting in an underestimation of overall economic activity by $50 \%$. Therefore, when measuring energy efficiency, the output indicator corresponding to capital, labor, energy, and other intermediate inputs is gross output. Gross output is more comprehensive, and focuses on the issue of resource consumption and therefore meets the requirements of sustainable development:

$$
\mathrm{GO}-\text { intermediate consumption }=\mathrm{GVA}
$$

Therefore, considering the impact of environmental pollution, the more comprehensive TFEE indicator framework constructed in this paper is as follows: capital, labor, energy consumption, other intermediate inputs, gross output and undesirable output.

\subsection{Data}

In this paper, we examine the paper industries in $22 \mathrm{EU}$ member states from 2008 to 2016 (France, Spain, Cyprus, Luxembourg, Malta and Croatia were excluded due to the absence of relevant data). The main data source is Eurostat, with the exception of the depreciation rate which is from the EU KLEMS database. All value variables are deflated with the 2010 price as the base year price. Main variables employed in this paper are as follows:

(1) Capital, the capital stock is used as capital input. Since there are no statistics on capital stock, the perpetual inventory method pioneered by Goldsmith in 1951 is adopted to estimate the annual value from 2008 to 2016 by using the following equation:

$$
K_{t}=K_{t-1} \times\left(1-\delta_{t}\right)+I_{t}
$$

where, $K_{t}$ and $K_{t-1}$ denote the capital stock of current year and previous year respectively, $\delta_{t}$ is the depreciation rate, and It is current investment. In this paper, fixed capital consumption in 2008 divided by the depreciation rate is used as the capital stock for the base year and gross investment in tangible goods is used as annual investment. As for the depreciation rate in EU paper industries, it is a fixed value of $10.6 \%$.

(2) Labor, the labor input indicator selected in this paper is personnel costs, which are defined as the total remuneration, in cash or in kind, payable by an employer to an employee in return for work done by the latter during the reference period.

(3) Energy consumption, the final energy consumption in the paper industries is used as energy input.

(4) Other intermediate consumption, is calculated as the value of total intermediate consumption minus the value of energy consumption.

(5) Output, corresponding to capital, labor, energy consumption and other intermediate consumption, gross output of paper industries is selected as desirable output. For the undesirable output, we only use waste residue and greenhouse gas as the data for 
wastewater is not available. Greenhouse gas is calculated by the sum of $\mathrm{CO}_{2}, \mathrm{~N}_{2} \mathrm{O}$, $\mathrm{CH}_{4}, \mathrm{HFC}, \mathrm{PFC}, \mathrm{SF}_{6}, \mathrm{NF}_{3}$ in $\mathrm{CO}_{2}$ equivalents.

Paper industries are considered to be one of the energy-intensive sectors. As we mentioned in the introduction, the European paper industries sector accounts for almost a quarter of the world's paper industries, both in production and consumption [5]. NACE Rev. 2 is the European industries standard classification, which is the same as International Standard Industrial Classification of All Economic Activities Revision 4 (ISIC, Rev.4). According to the classification of economic activities in NACE rev.2, under section C manufacturing, there are two sub-industries related to papermaking, namely, division 17Manufacture of paper and paper products, and division 18- Printing and reproduction of recorded media. A more detailed breakdown is presented in Table 1. The paper industries sector is defined in this paper as the sum of the two sub-industries of manufacture of paper and paper products and the printing and reproduction of recorded media. Descriptive statistics on the input and output of the paper industries in the EU are shown in Tables A1 and $\mathrm{A} 2$, respectively.

Table 1. Detailed classification in paper industries.

\begin{tabular}{ccc}
\hline Division & Group & Description \\
\hline 17 & & Manufacture of paper and paper products \\
& 17.1 & Manufacture of pulp, paper and paperboard \\
Manufacture of articles of paper and paperboard & Printing and reproduction of recorded media \\
18 & 17.2 & Printing and service activities related to printing \\
& 18.1 & Reproduction of recorded media \\
\hline
\end{tabular}

\section{Empirical Efficiency Measurement}

In this paper, both input-oriented CCR model and SBM are employed to measure TFEE. In the CCR model, all inputs must adjust proportionally without reducing output, while the SBM model is a non-radial DEA method, which directly deals with the problem of input and undesirable output redundancy as well as desirable output deficiency. Therefore, the SBM model has more advantages in measuring energy redundancy as well as optimal energy input. The energy efficiency results of the CCR model are shown in Table 2 below. Overall, average energy efficiency value shows an upward trend with an improvement of $10.8 \%$, from $76.3 \%$ in 2008 to $87.1 \%$ in 2016 . In terms of all countries' average during the period, the energy efficiency of EU paper industries was found to be $81.9 \%$, which indicates that it would be possible to make all the inputs decrease proportionally by $18.1 \%$ while keeping the original output unchanged. Specifically, nine countries out of 22 can reduce all inputs proportionally by even more than the average level of $18.1 \%$. It can be observed that four of these countries, respectively Ireland, Latvia, Lithuania and Slovakia, are always energy efficient, with energy efficiency of 1 per year. The lowest efficiency value was Finland, with the highest saving potential of $57.3 \%$. The reason is that Finland has high forest coverage, so wood processing related industries are very developed, but its paper industry has always been known for its excessive energy consumption and heavy pollution. Besides, countries like Estonia and Sweden can also reduce energy consumption by about $40 \%$.

By finding the maximum distance to frontier, SBM based TFEE of $22 \mathrm{EU}$ countries are presented in Table 3. The SBM model has better discriminatory power in energy efficiency measurement than the CCR model and will provide maximum potential for energy saving through a non-radial reduction in all inputs [33]. Overall, the average TFEE value is $70.3 \%$, indicating that these 22 countries still have $29.7 \%$ potential for savings, which accounts for a large part of the total energy consumption in Europe, equivalent to 100,000 Gigawatt-hours (Gwh) of electricity. From 2008 to 2010, energy efficiency increased dramatically, from $62 \%$ to $79 \%$ due mainly to the improved performance and economic recovery after the 
2008 financial crisis. The decline in energy efficiency that began in 2011 was caused by the negative impact of a Europe-wide economic downturn on European paper industries [5]. Following a gradual decrease between 2011 and 2014, energy efficiency increased between 2014 and 2016. The increase could partly be attributed to good economic performance since 2014 and low oil prices. From the perspective of individual countries, energy efficiency varies widely, from 0.331 to 1 . Ireland, Latvia, Lithuania and Slovakia have the most efficient paper industries, while Slovenia, Finland, Estonia, Austria and Belgium all have low energy efficiency values, with more than $50 \%$ energy reduction space.

Table 2. Annual TFEE of 22 EU countries under the CCR model.

\begin{tabular}{|c|c|c|c|c|c|c|c|c|c|c|}
\hline \multirow{2}{*}{ Country } & \multicolumn{9}{|c|}{ Year } & \multirow{2}{*}{ Average } \\
\hline & 2008 & 2009 & 2010 & 2011 & 2012 & 2013 & 2014 & 2015 & 2016 & \\
\hline Belgium & 0.763 & 0.795 & 0.799 & 0.711 & 0.697 & 0.717 & 0.755 & 0.787 & 0.815 & 0.760 \\
\hline Bulgaria & 0.276 & 0.647 & 0.323 & 1.000 & 1.000 & 1.000 & 0.932 & 0.795 & 0.899 & 0.764 \\
\hline Czechia & 0.701 & 0.790 & 0.776 & 0.551 & 0.819 & 0.844 & 0.892 & 0.892 & 0.901 & 0.796 \\
\hline Denmark & 0.918 & 0.851 & 0.929 & 0.810 & 0.887 & 0.871 & 0.886 & 0.865 & 0.927 & 0.883 \\
\hline Germany & 0.773 & 0.796 & 0.827 & 0.788 & 0.707 & 0.765 & 0.638 & 0.662 & 0.642 & 0.733 \\
\hline Estonia & 0.524 & 0.463 & 0.609 & 0.656 & 0.418 & 1.000 & 0.609 & 0.599 & 0.433 & 0.590 \\
\hline Ireland & 1.000 & 1.000 & 1.000 & 1.000 & 1.000 & 1.000 & 1.000 & 1.000 & 1.000 & 1.000 \\
\hline Greece & 0.998 & 0.880 & 0.961 & 0.908 & 0.840 & 0.845 & 0.838 & 0.882 & 1.000 & 0.906 \\
\hline Italy & 0.795 & 0.819 & 0.972 & 0.915 & 0.814 & 0.818 & 0.849 & 0.841 & 0.986 & 0.868 \\
\hline Latvia & 1.000 & 1.000 & 1.000 & 1.000 & 1.000 & 1.000 & 1.000 & 1.000 & 1.000 & 1.000 \\
\hline Lithuania & 1.000 & 1.000 & 1.000 & 1.000 & 1.000 & 1.000 & 1.000 & 1.000 & 1.000 & 1.000 \\
\hline Hungary & 0.775 & 0.776 & 0.984 & 0.869 & 0.825 & 0.834 & 0.852 & 0.853 & 0.873 & 0.849 \\
\hline Netherlands & 0.790 & 0.825 & 0.882 & 0.882 & 0.813 & 0.788 & 0.797 & 0.786 & 0.934 & 0.833 \\
\hline Austria & 0.681 & 0.805 & 0.777 & 0.713 & 0.644 & 0.678 & 0.650 & 0.716 & 0.837 & 0.722 \\
\hline Poland & 0.712 & 0.741 & 0.772 & 0.411 & 1.000 & 1.000 & 1.000 & 1.000 & 1.000 & 0.848 \\
\hline Portugal & 0.596 & 0.743 & 0.833 & 0.611 & 0.787 & 0.823 & 1.000 & 1.000 & 1.000 & 0.821 \\
\hline Romania & 1.000 & 1.000 & 1.000 & 1.000 & 1.000 & 1.000 & 0.947 & 0.875 & 0.863 & 0.965 \\
\hline Slovenia & 0.771 & 0.782 & 0.714 & 0.713 & 0.755 & 0.759 & 0.801 & 0.810 & 0.832 & 0.771 \\
\hline Slovakia & 1.000 & 1.000 & 1.000 & 1.000 & 1.000 & 1.000 & 1.000 & 1.000 & 1.000 & 1.000 \\
\hline Finland & 0.385 & 0.409 & 0.366 & 0.354 & 0.404 & 0.423 & 0.444 & 0.498 & 0.562 & 0.427 \\
\hline Sweden & 0.472 & 0.470 & 0.564 & 0.575 & 0.527 & 0.601 & 0.643 & 0.689 & 0.664 & 0.578 \\
\hline United Kingdom & 0.859 & 0.891 & 0.960 & 0.872 & 0.852 & 0.873 & 0.877 & 1.000 & 1.000 & 0.909 \\
\hline Average & 0.763 & 0.795 & 0.820 & 0.788 & 0.809 & 0.847 & 0.837 & 0.843 & 0.871 & 0.819 \\
\hline
\end{tabular}

Table 3. Annual TFEE of 22 EU countries under SBM model.

\begin{tabular}{ccccccccccc}
\hline \multirow{2}{*}{ Country } & \multicolumn{7}{c}{ Year } & \multirow{2}{*}{ Average } \\
\cline { 2 - 8 } & $\mathbf{2 0 0 8}$ & $\mathbf{2 0 0 9}$ & $\mathbf{2 0 1 0}$ & $\mathbf{2 0 1 1}$ & $\mathbf{2 0 1 2}$ & $\mathbf{2 0 1 3}$ & $\mathbf{2 0 1 4}$ & $\mathbf{2 0 1 5}$ & $\mathbf{2 0 1 6}$ & \\
\hline Belgium & 0.403 & 0.777 & 0.547 & 0.455 & 0.348 & 0.348 & 0.235 & 0.587 & 0.617 & 0.480 \\
Bulgaria & 0.185 & 0.511 & 0.439 & 1.000 & 1.000 & 1.000 & 0.872 & 0.646 & 0.776 & 0.714 \\
Czechia & 0.327 & 0.603 & 0.541 & 0.436 & 0.294 & 0.305 & 0.723 & 0.690 & 0.773 & 0.521 \\
Denmark & 1.000 & 0.919 & 0.966 & 0.969 & 0.851 & 0.828 & 0.741 & 0.648 & 0.919 & 0.871 \\
Germany & 0.515 & 0.735 & 0.851 & 0.683 & 0.459 & 0.403 & 0.334 & 0.327 & 0.543 & 0.539 \\
Estonia & 0.370 & 0.397 & 0.603 & 0.416 & 0.338 & 1.000 & 0.211 & 0.204 & 0.262 & 0.422 \\
Ireland & 1.000 & 1.000 & 1.000 & 1.000 & 1.000 & 1.000 & 1.000 & 1.000 & 1.000 & 1.000 \\
Greece & 1.000 & 1.000 & 1.000 & 1.000 & 0.684 & 0.640 & 0.674 & 0.772 & 1.000 & 0.863 \\
Italy & 0.659 & 0.947 & 1.000 & 0.970 & 0.555 & 0.536 & 0.480 & 0.490 & 0.726 & 0.707 \\
Latvia & 1.000 & 1.000 & 1.000 & 1.000 & 1.000 & 1.000 & 1.000 & 1.000 & 1.000 & 1.000 \\
Lithuania & 1.000 & 1.000 & 1.000 & 1.000 & 1.000 & 1.000 & 1.000 & 1.000 & 1.000 & 1.000 \\
Hungary & 0.654 & 0.603 & 1.000 & 0.808 & 0.329 & 0.356 & 0.234 & 0.470 & 0.509 & 0.551 \\
Netherlands & 0.667 & 0.714 & 1.000 & 0.963 & 0.630 & 0.502 & 0.594 & 0.617 & 0.935 & 0.736 \\
\hline
\end{tabular}


Table 3. Cont.

\begin{tabular}{ccccccccccc}
\hline \multirow{2}{*}{ Country } & \multicolumn{9}{c}{ Year } & \multirow{2}{*}{ Average } \\
\cline { 2 - 9 } & $\mathbf{2 0 0 8}$ & $\mathbf{2 0 0 9}$ & $\mathbf{2 0 1 0}$ & $\mathbf{2 0 1 1}$ & $\mathbf{2 0 1 2}$ & $\mathbf{2 0 1 3}$ & $\mathbf{2 0 1 4}$ & $\mathbf{2 0 1 5}$ & $\mathbf{2 0 1 6}$ & \\
\hline Austria & 0.312 & 0.674 & 0.505 & 0.391 & 0.292 & 0.282 & 0.227 & 0.499 & 0.606 & 0.421 \\
Poland & 0.339 & 0.531 & 0.763 & 0.410 & 1.000 & 1.000 & 1.000 & 1.000 & 1.000 & 0.783 \\
Portugal & 0.497 & 0.691 & 0.833 & 0.677 & 0.732 & 0.922 & 1.000 & 1.000 & 1.000 & 0.817 \\
Romania & 1.000 & 1.000 & 1.000 & 1.000 & 1.000 & 1.000 & 0.935 & 0.404 & 1.000 & 0.927 \\
Slovenia & 0.288 & 0.657 & 0.407 & 0.338 & 0.261 & 0.282 & 0.213 & 0.311 & 0.224 & 0.331 \\
Slovakia & 1.000 & 1.000 & 1.000 & 1.000 & 1.000 & 1.000 & 1.000 & 1.000 & 1.000 & 1.000 \\
Finland & 0.312 & 0.329 & 0.396 & 0.372 & 0.361 & 0.520 & 0.388 & 0.432 & 0.429 & 0.393 \\
Sweden & 0.421 & 0.420 & 0.535 & 0.563 & 0.523 & 0.774 & 0.524 & 0.539 & 0.524 & 0.536 \\
United Kingdom & 0.691 & 1.000 & 1.000 & 0.858 & 0.715 & 0.724 & 0.652 & 1.000 & 1.000 & 0.849 \\
Average & 0.620 & 0.750 & 0.790 & 0.741 & 0.653 & 0.701 & 0.638 & 0.665 & 0.766 & 0.703 \\
\hline
\end{tabular}

For comparative analysis with TFEE, we also used available data from 2008 to 2016 to estimate SFEE: energy intensity. The smaller the value of energy intensity, the higher the efficiency. At a specific industry level, energy intensity is equal to the ratio of energy consumption to industry's added value, with the estimated results shown in Table 4. Energy consumption is converted into electricity, and the unit is Gigawatt-hour. It can be seen from Table 4 that the average energy intensity of 22 countries shows an overall upward trend, indicating a decline in SFEE. The average value is 5.8 , which means that for every one million euros increase in the output of the paper industries, an average of 5.8 Gigawatt-hour of energy is required. From a national perspective, energy intensity varies widely, with the lowest being Ireland, at 0.5; the highest being Finland, at 19.69. Overall, the energy intensity of the paper industries fell in 12 of the 22 member countries, indicating improved efficiency. The largest fall in energy intensity was recorded in Czechia $(-0.93 \%)$, followed by Estonia $(-0.75 \%)$ and Netherlands $(-0.74 \%)$. Among the remaining 10 Member States where energy intensity increased from 2008 to 2016, the highest increase was registered in Finland $(+3.16 \%)$, followed by Bulgaria $(+3.12 \%)$, Portugal $(+1.83 \%)$.

Table 4. Energy intensity.

\begin{tabular}{|c|c|c|c|c|c|c|c|c|c|c|}
\hline \multirow{2}{*}{ Countries } & \multicolumn{9}{|c|}{ Year } & \multirow{2}{*}{ Average } \\
\hline & 2008 & 2009 & 2010 & 2011 & 2012 & 2013 & 2014 & 2015 & 2016 & \\
\hline Belgium & 3.65 & 4.22 & 4.22 & 3.73 & 3.71 & 4.14 & 4.01 & 4.07 & 4.46 & 4.02 \\
\hline Bulgaria & 9.91 & 4.32 & 10.80 & 11.35 & 11.30 & 13.41 & 12.20 & 13.95 & 13.03 & 11.14 \\
\hline Czechia & 6.16 & 6.37 & 5.74 & 5.91 & 6.31 & 6.40 & 6.13 & 5.77 & 5.23 & 6.00 \\
\hline Denmark & 1.36 & 1.62 & 1.86 & 1.54 & 1.17 & 1.36 & 1.08 & 1.17 & 1.10 & 1.36 \\
\hline Germany & 3.91 & 4.18 & 4.14 & 3.97 & 3.64 & 3.73 & 3.73 & 3.57 & 3.49 & 3.82 \\
\hline Estonia & 5.48 & 6.52 & 6.33 & 6.10 & 5.44 & 5.24 & 5.07 & 5.20 & 4.73 & 5.57 \\
\hline Ireland & 0.40 & 0.50 & 0.52 & 0.52 & 0.49 & 0.51 & 0.48 & 0.53 & 0.58 & 0.50 \\
\hline Greece & 1.33 & 1.46 & 1.93 & 1.83 & 2.00 & 2.42 & 2.56 & 2.41 & 1.45 & 1.93 \\
\hline Italy & 2.91 & 3.06 & 2.85 & 2.59 & 2.75 & 2.46 & 2.71 & 2.96 & 2.68 & 2.77 \\
\hline Latvia & 1.01 & 1.53 & 1.29 & 1.21 & 0.96 & 1.02 & 0.65 & 0.63 & 0.61 & 0.99 \\
\hline Lithuania & 1.48 & 2.50 & 3.24 & 2.20 & 1.50 & 1.53 & 1.20 & 0.99 & 1.12 & 1.75 \\
\hline Hungary & 3.61 & 3.14 & 3.36 & 3.57 & 4.06 & 4.56 & 4.63 & 4.48 & 4.74 & 4.02 \\
\hline Netherlands & 2.63 & 2.27 & 2.40 & 2.24 & 2.36 & 2.28 & 1.98 & 1.90 & 1.89 & 2.22 \\
\hline Austria & 6.59 & 7.02 & 6.97 & 6.32 & 5.91 & 6.45 & 6.32 & 6.29 & 6.48 & 6.48 \\
\hline Poland & 6.09 & 5.56 & 5.42 & 5.06 & 4.89 & 5.86 & 5.40 & 5.30 & 5.52 & 5.46 \\
\hline Portugal & 8.98 & 9.91 & 9.82 & 10.16 & 11.38 & 11.73 & 10.89 & 10.59 & 10.81 & 10.47 \\
\hline Romania & 1.39 & 1.04 & 2.52 & 1.06 & 1.63 & 1.68 & 2.50 & 2.66 & 2.64 & 1.90 \\
\hline Slovenia & 7.29 & 7.47 & 7.27 & 6.74 & 6.90 & 7.05 & 6.65 & 6.70 & 7.07 & 7.02 \\
\hline Slovakia & 12.69 & 13.96 & 13.38 & 14.09 & 10.04 & 11.57 & 12.37 & 15.22 & 13.70 & 13.00 \\
\hline Finland & 17.52 & 22.54 & 19.12 & 19.95 & 19.27 & 19.15 & 18.84 & 20.15 & 20.68 & 19.69 \\
\hline Sweden & 15.63 & 16.69 & 14.96 & 15.27 & 14.93 & 15.59 & 10.68 & 16.94 & 16.15 & 15.20 \\
\hline United Kingdom & 2.45 & 2.17 & 2.10 & 2.14 & 2.21 & 2.24 & 2.20 & 1.96 & 2.18 & 2.18 \\
\hline Average & 5.57 & 5.82 & 5.92 & 5.80 & 5.58 & 5.93 & 5.56 & 6.07 & 5.92 & \\
\hline
\end{tabular}


As shown in Figure 1, three trend lines representing average efficiency for TFEE-CCR, TFEE-SBM and EI are generally upward. Among them, the energy efficiency estimated by CCR model is $10 \%$ higher on average than that of SBM model, albeit the trend is roughly the same. As shown in Table 5, TFEE under CCR and SBM model have significant correlation with the correlation coefficient of 0.837 . Based on this observation, it is believed that SBM has a more discriminatory power and hence provides efficiency scores lower than those of CCR measurement of efficiency. Because SBM measures not only the decrease of input, but also the increase of output, it directly aims at maximizing the average slack. Therefore, when there is no output slack, the efficiency values measured by SBM and CCR are the same. When there is output slack, the CCR model would overestimate energy efficiency to some extent. On the one hand, SBM TFEE can provide a smaller energy efficiency score, that is, a greater potential for saving. On the other hand, SBM TFEE can directly show how much energy is wasted, so we believe that SBM efficiency is more suitable for policy makers. In addition, the trend line of energy intensity is similar to the trend of TFEE, but its fluctuation is more drastic. Because the greater the energy intensity, the less the energy efficiency, SFEE represented by energy intensity is opposite to TFEE and is inconsistent with the actual situation: SFEE declined in the economic recovery stage after the financial crisis in 2008 and the economic boom stage in 2014, while it increased in the economic downturn in Europe in 2011. As previously mentioned, energy intensity represents only the proportional relationship between gross value added and energy consumption, and it does have inevitable defects in measuring energy efficiency.

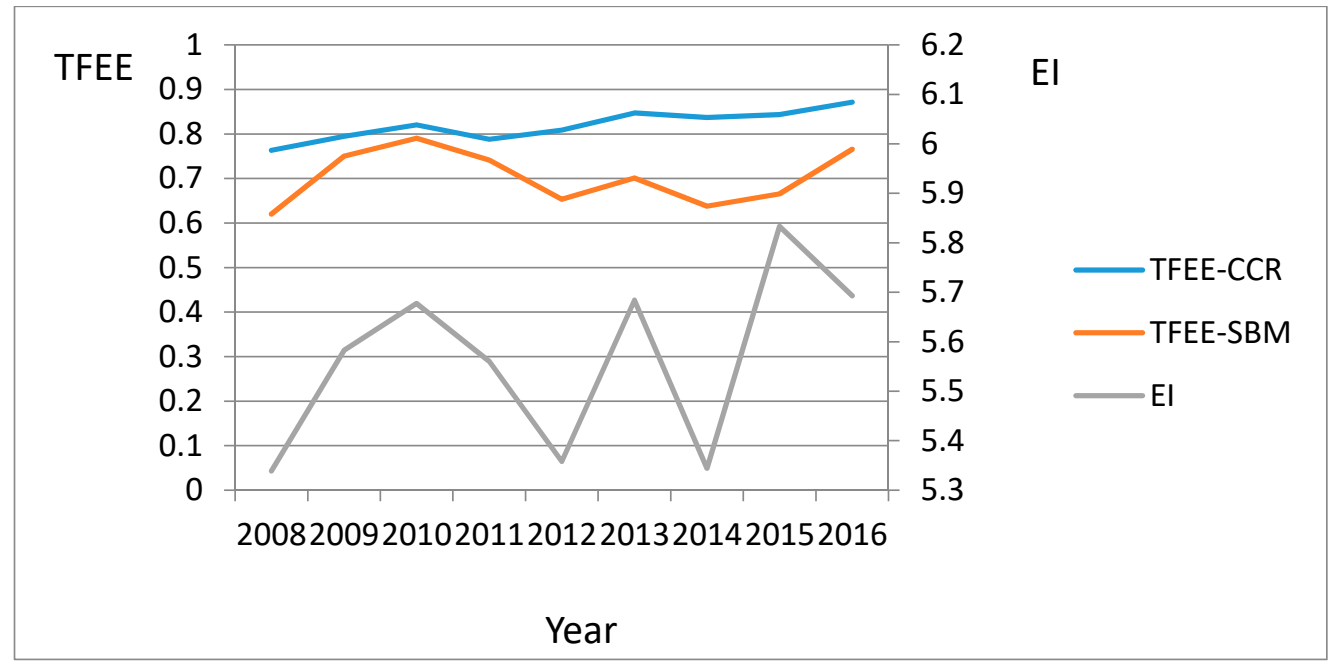

Figure 1. Average efficiency trend from 2008 to 2016.

Table 5. Annual TFEE of 22 EU countries under SBM model.

\begin{tabular}{ccc}
\hline & TFEE (CCR) & TFEE (SBM) \\
\hline TFEE $($ CCR) & 1 & $0.837^{* *}$ \\
TFEE (SBM) & $0.837^{* *}$ & 1 \\
\hline \multicolumn{2}{c}{ Note: $^{* *}$ mean extremely correlation at $p<0.01}$.
\end{tabular}

According to the results of Tables 2 and 3, TFEE values for Estonia indicate a large jump between 2012 and 2013. In the CCR model, TFEE for these two years are 0.418 and 1, respectively. This is caused by overall efficiency of radial adjustment, which was 0.887 in 2012 and 1 in 2013. On the other hand, this is caused by the slack of non-radial adjustment, which was 84 in 2012, while 0 in 2013 due to the overall efficiency value of 1 . In the SBM model, TFEE in these two years are 0.338 and 1 . Specifically, factor inputs fell by $3.5 \%$ and output rose by $21 \%$, thus resulting in a sharp increase in TFEE in 2013. 


\section{Target for Energy Efficiency and Emission Reduction}

In addition to measuring the TFEE of SBM in paper industries of EU countries, we also calculate the energy saving potential and the greenhouse gas emission reduction potential under the SBM model, providing theoretical possibility in 2030 target for energy efficiency and emission reduction and a reference point for policy makers.

\subsection{Target for Energy Efficiency}

The EU has committed itself to a 32.5\% improvement in energy efficiency from 2021 to 2030 . This objective is also known as the $32.5 \%$ energy saving target, which translates into an annual energy savings of at least $3.85 \%$. In the case of economic growth, energy saving should first cope with increased energy consumption. Assuming that the average economic growth rate from 2021 to 2030 is the same as that from 2010 to 2019 , at $2.33 \%$, paper industries need to save at least $6.18 \%(3.85 \%+2.33 \%)$ of energy consumption per year.

As can be seen from Table A3, the energy saving potential of each country varies greatly. Finland, Sweden, and Germany have the largest energy saving potential, with an average of $34,724 \mathrm{Gwh}$ of electricity. This is not only related to the size of the paper industries and its huge energy consumption, but is also related to its energy efficiency. Ireland, Latvia, Lithuania and Slovakia have the highest energy efficiency, resulting in no potential for energy saving. Although they are all small countries, it can be seen from the input-output table that they have a good ratio among the inputs of various factors. From 2008 to 2016, the annual total energy saving potential of the paper industries in the EU showed a downward trend. While the total energy consumption remained basically unchanged, the decline of energy saving potential reflected the rise of energy efficiency. The absolute value of energy saving potential has declined, but it still accounts for a large share of total energy consumption, from more than $50 \%$ in 2008 to more than one-third thereafter, which is well above the $6.18 \%$ energy saving target. In order to achieve the 2030 energy target, the EU paper industry needs to save at least $6.18 \%$ of energy consumption annually. However, if all countries' paper industries can achieve their best in energy efficiency, $33 \%$ energy could be saved annually.

\subsection{Target for Emission Reduction}

EU has set a $40 \%$ target for emission cuts by 2030 , which translates into an annual emission reduction of $1.37 \%$. In the case of economic growth, EU should first cope with the increased energy consumption that is generated by economic growth in order to achieve the emission reduction target. Assuming that the average economic growth rate from 2021 to 2030 is the same as from 2010 to 2019 , at $2.33 \%$, paper industries need to reduce emissions by at least $3.7 \%(1.37 \%+2.33 \%)$ per annum to ensure that the EU as a whole meets its 2030 target.

Table A4 shows the greenhouse gas emission reduction potential of paper industries in each country. Except for Ireland, Latvia, Lithuania and Slovakia, which have zero emission reduction potential, the greenhouse gas emission reduction potential of other countries is quite large. The overall emission potential has declined, and the emission reduction rate has dropped from $96.9 \%$ to $70.9 \%$, which is also well above the $3.7 \%$ reduction target for 2030. The average emission reduction potential is $71 \%$. In addition, the greenhouse gas emission reduction potential of most countries accounts for more than $90 \%$ of the actual emissions for the year, which indicates that the environmental problems can be greatly resolved by improving energy efficiency and reducing fossil energy use while maintaining the original output.

\subsection{Discussion}

According to TFEE of paper industries measured in this paper, the $22 \mathrm{EU}$ countries are divided into three groups: high-value group, low-value group and medium-value group. The average annual energy saving potential and average annual emission reduction of 
each country from 2008 to 2016 are shown in Figure 2. Countries in the high-value group are countries with TFEE of 1 , including Ireland, Latvia, Lithuania and Slovakia. These four countries are always at the frontier, with no potential for energy saving and emission reduction, and they are the targets for other countries to follow. Countries with lower energy efficiency than average are classified to be in the low-value group, which includes Hungary, Germany, Sweden, the Czech Republic, Belgium, Estonia, Austria, Finland and Slovenia. The average energy efficiency of these countries is $46.6 \%$, indicating a $53.4 \%$ energy saving potential. That is equivalent to $125,473 \mathrm{Gwh}$ of power savings. It is worth noting that Germany has a large paper industry with all inputs ranking first (except energy), but its TFEE is $53.9 \%$, with $46.1 \%$ of energy saving potential, accounting for $21.5 \%$ of the total energy saving potential of EU paper industries. Finland and Sweden are the main pulping and papermaking countries in Northern Europe. Their energy inputs rank first and third in the paper industries respectively. Due to the large energy input base and large energy saving potential, which are $60.7 \%$ and $46.4 \%$ respectively, the improvement of energy efficiency of the paper industries in Finland and Sweden is of great significance to energy saving for the EU paper industry, accounting for $50 \%$ of the total energy saving potential. In addition, as Finland's paper industry is known for its high energy consumption and heavy pollution, accounting for $57 \%$ of manufacturing industry's energy consumption in 2016, its energy efficiency improvement also plays a key role in this country's energy saving targets. Finland and Sweden account for $17.1 \%$ of the greenhouse gas emission reduction potential of EU paper industries, so the improvement of energy efficiency in these two countries could also improve the environment. Moreover, Finland and Sweden, despite their high energy consumption, are relatively efficient in reducing emissions. The third group is the medium-value, with TFEE ranging from average to 1, and it includes Romania, Denmark, Greece, the United Kingdom, Portugal, Poland, Netherlands, Bulgaria and Italy. The average TFEE is $80.7 \%$, with an energy saving potential of $19.3 \%$. Specifically, it saves 20,129 Gwh of electricity and 11,485,532 tons of greenhouse gas emissions per year on average. As for the percentage, the medium-value group saved $13.8 \%$ of its potential energy savings, but $41.4 \%$ of greenhouse gas emissions, suggesting that the paper industries in the low-value group did better in reducing emissions than the medium-value group. UK paper industries investment was relatively large and energy efficiency was high, reaching $84.9 \%$.

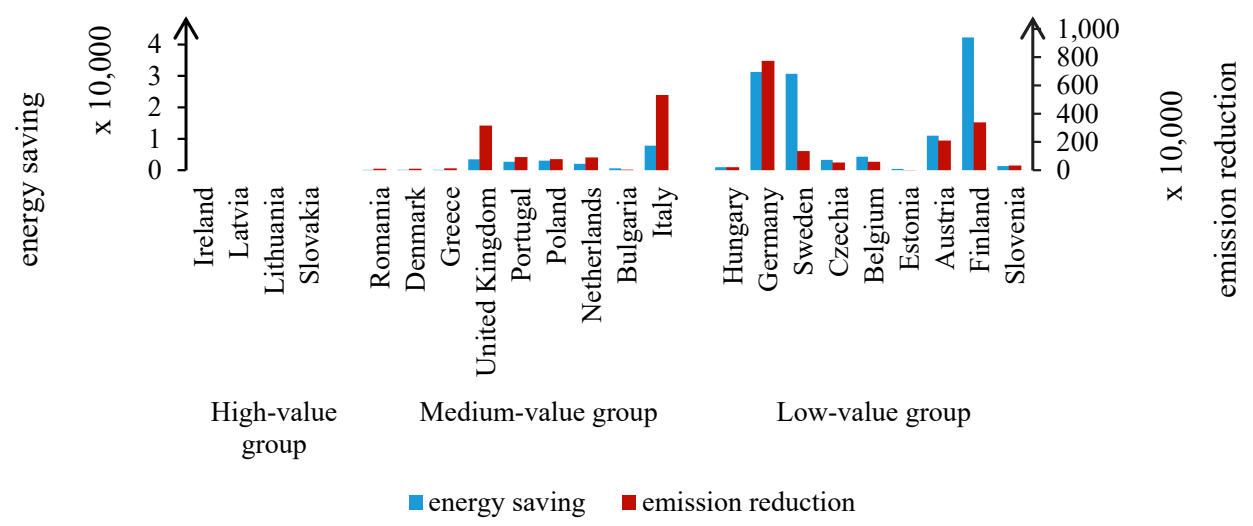

Figure 2. High-value, medium-value and low-value group of TFEE.

The overall energy price (inclusive of non-recoverable taxes) is closely related to energy efficiency. High energy price countries such as the UK (0.165 Euro/Kwh), Ireland (0.133 Euro/Kwh), Italy (0.150 Euro/Kwh) and Slovakia (0.132 Euro/Kwh) have relatively high energy efficiency, while Finland (0.070 Euro/Kwh), Sweden (0.065 Euro/Kwh) have low energy prices, more energy inputs, higher energy intensity (E/VA) and lower TFEE values. However, it is worth noting that Germany is an exception with the highest energy price (0.178 Euro/Kwh) but low energy efficiency, which needs a further investigation. Generally speaking, low energy price is closely related to low energy efficiency. Another important finding is that the countries with large scale paper industries have greater potential 
for energy saving and emission reduction. Due to high forest coverage rate and rich timber resources, Finland and Sweden have sufficient raw materials and therefore large scale paper industries. They can save as many as 72,890 Gwh of energy and reduce 4,742,101 tonnes emissions annually. In addition, other large scale paper industries countries like Germany (energy saving: 31,281 Gwh, emission reduction: 7,734,054 tonnes), United Kingdom (emission reduction: 3,155,538 tonnes) and Italy (emission reduction: 5,323,883 tonnes) also have large potential for energy saving and emission reduction. Overall, these five countries can save 115,487 Gwh of energy and reduce 20,955,576 tonnes of emissions per year if their TFEE value could reach 1, accounting for 79\% of energy savings and $75 \%$ of total emissions reductions in the EU paper industry.

It is believed that EU policy makers should raise energy consumption cost (prices or non-recoverable taxes), thereby encouraging energy-intensive countries to actively seek ways to improve energy efficiency or increase the share of renewable energy. As for energy saving, the EU should focus more on major paper producing countries, such as Finland, Sweden, and Germany. As for emission reduction the EU should focus more on countries like Germany, United Kingdom, Italy and Finland. These five countries have a greater potential for energy saving and emission reduction, which is critical to achieve the EU's 2030 targets.

\section{Conclusions}

Improving energy efficiency has become the key solution for economic development, energy saving and environmental problems at the same time. Therefore, this paper aims to measure the energy efficiency of paper industries in EU countries, estimate potential energy saving and emission reduction, and make a comparison with the 2030 targets. The following are the conclusions: (1) SBM and CCR efficiency value is more meaningful for policy makers than that of energy intensity, as measurement results of energy intensity deviate from reality and economic efficiency. (2) By applying a complete set of input and output indicators, we estimate that average TFEE for EU paper industry under SBM is 0.71 , and countries like Ireland, Latvia, Lithuania and Slovakia are examples that should be followed by others, for they are always at the frontier of efficiency. (3) When paper industries in every EU country make efficient use of energy by referring to countries on the frontier, they have an energy saving potential (of at least 33\%) and emission reduction potential (of at least 71\%) annually, which is well above the EU 2021-2030 target of $6.18 \%$ and $3.17 \%$.

Furthermore, the $22 \mathrm{EU}$ countries are divided into high-value, medium-value and low-value groups according to the energy efficiency level, and another important finding is that among them, the low-value group has the greatest energy saving potential, especially for countries like Finland, Sweden and Germany, which EU and relevant governments should focus more on to improve energy efficiency in those countries. At the same time, countries in the medium-value group like Italy and United Kingdom still need to make efforts to reduce greenhouse gas emissions.

For individual countries, it is suggested that EU policy makers should raise energy consumption cost by increasing energy prices or non-recoverable taxes, encourage energyintensive countries to actively seek ways to improve energy efficiency and increase the usage of renewable energy. As for energy saving and emission reduction, the EU should focus more on major paper producing countries, such as Finland, Sweden, Germany, United Kingdom, and Italy, which have greater potentials in energy saving and emission reduction. This is critical for the EU to achieve the 2030 targets.

Author Contributions: Conceptualization, S.L., L.W. and L.L.; methodology, S.L. and L.L.; software, L.L.; validation, S.L. and L.W.; formal analysis, S.L. and L.L.; investigation, L.L.; resources, L.L.; data curation, L.L.; writing—original draft preparation, L.L.; writing—review and editing, S.L. and L.W.; visualization, L.L.; supervision, S.L. and L.W.; project administration, S.L.; funding acquisition, S.L. and L.W. All authors have read and agreed to the published version of the manuscript. 
Funding: This research received no external funding.

Conflicts of Interest: The authors declare no conflict of interest.

Appendix A

Table A1. Descriptive statistics of inputs.

\begin{tabular}{|c|c|c|c|c|c|c|c|c|}
\hline \multirow{3}{*}{ Country } & \multicolumn{8}{|c|}{ Inputs } \\
\hline & \multicolumn{2}{|c|}{$\begin{array}{c}\text { Capital } \\
\text { (Million Euro) }\end{array}$} & \multicolumn{2}{|c|}{$\begin{array}{c}\text { Labor } \\
\text { (Million Euro) }\end{array}$} & \multicolumn{2}{|c|}{$\begin{array}{l}\text { Energy Consumption } \\
\text { (Gigawatt-Hour) }\end{array}$} & \multicolumn{2}{|c|}{$\begin{array}{c}\text { Other Intermediate } \\
\text { Consumption } \\
\text { (Million Euro) }\end{array}$} \\
\hline & Mean & SD & Mean & SD & Mean & SD & Mean & SD \\
\hline Belgium & 5686 & 588 & 1388 & 158 & 8340 & 332 & 4374 & 373 \\
\hline Bulgaria & 527 & 53 & 82 & 12 & 2355 & 630 & 343 & 54 \\
\hline Czechia & 2565 & 76 & 539 & 47 & 6901 & 144 & 2130 & 222 \\
\hline Denmark & 1789 & 263 & 654 & 121 & 1226 & 375 & 1536 & 169 \\
\hline Germany & 30,214 & 3065 & 12,150 & 561 & 68,436 & 2478 & 32,709 & 2605 \\
\hline Estonia & 201 & 9 & 59 & 5 & 700 & 58 & 217 & 14 \\
\hline Ireland & 986 & 113 & 385 & 61 & 291 & 12 & 1024 & 313 \\
\hline Greece & 1047 & 110 & 411 & 87 & 1163 & 309 & 1241 & 92 \\
\hline Italy & 18,327 & 2214 & 5249 & 383 & 27,091 & 1778 & 20,314 & 1341 \\
\hline Latvia & 210 & 5 & 40 & 6 & 86 & 25 & 187 & 24 \\
\hline Lithuania & 201 & 56 & 73 & 15 & 402 & 105 & 230 & 66 \\
\hline Hungary & 1337 & 133 & 293 & 35 & 2041 & 268 & 1248 & 124 \\
\hline Netherlands & 6339 & 1028 & 2090 & 199 & 7808 & 1002 & 6863 & 355 \\
\hline Austria & 5050 & 501 & 1607 & 75 & 19,016 & 626 & 4169 & 394 \\
\hline Poland & 5782 & 562 & 1069 & 119 & 16,155 & 2178 & 5638 & 968 \\
\hline Portugal & 3495 & 298 & 548 & 80 & 15,277 & 761 & 1884 & 232 \\
\hline Romania & 1101 & 180 & 204 & 49 & 1248 & 369 & 923 & 161 \\
\hline Slovenia & 790 & 84 & 184 & 19 & 2026 & 130 & 615 & 43 \\
\hline Slovakia & 1359 & 348 & 182 & 7 & 5821 & 789 & 512 & 171 \\
\hline Finland & 9485 & 1577 & 1828 & 255 & 69,534 & 4138 & 6335 & 622 \\
\hline Sweden & 11,118 & 808 & 2737 & 257 & 66,102 & 7897 & 6488 & 733 \\
\hline United Kingdom & 13,431 & 1261 & 5712 & 602 & 22,182 & 2123 & 14,559 & 1450 \\
\hline
\end{tabular}

Table A2. Descriptive statistics of outputs.

\begin{tabular}{ccccccc}
\hline & \multicolumn{9}{c}{ Outputs } \\
\cline { 2 - 7 } Country & \multicolumn{2}{c}{$\begin{array}{c}\text { Gross Output } \\
\text { (Million Euro) }\end{array}$} & \multicolumn{2}{c}{$\begin{array}{c}\text { Waste Residue } \\
\text { (Tonne) }\end{array}$} & $\begin{array}{c}\text { Greenhouse Gas } \\
\text { (Tonne) }\end{array}$ \\
\cline { 2 - 7 } & Mean & SD & Mean & SD & Mean & SD \\
\hline Belgium & 7197 & 479 & 946,510 & 348,782 & 600,867 & 65,898 \\
Bulgaria & 725 & 88 & 86,701 & 41,826 & 176,075 & 45,886 \\
Czechia & 3900 & 310 & 319,678 & 16,896 & 555,491 & 75,419 \\
Denmark & 2515 & 341 & 131,382 & 32,063 & 115,566 & 21,011 \\
Germany & 56,442 & 3728 & $3,554,700$ & 310,871 & $7,734,987$ & 730,705 \\
Estonia & 373 & 24 & 109,967 & 12,476 & 71,021 & 18,027 \\
Ireland & 1607 & 346 & 145,829 & 116,137 & 3543 \\
Greece & 1998 & 333 & 116,700 & 36,265 & 157,264 & 5174 \\
Italy & 32,851 & 2198 & $1,903,056$ & 131,816 & $5,324,694$ & 324,764 \\
Latvia & 283 & 26 & 7614 & 3772 & 124,995 & 17,399 \\
Lithuania & 502 & 106 & 50,620 & 11,409 & 45,381 & 14,807 \\
Hungary & 1977 & 148 & 207,565 & 52,180 & 228,923 \\
\hline
\end{tabular}


Table A2. Cont.

\begin{tabular}{ccccccc}
\hline & \multicolumn{9}{c}{ Outputs } \\
\cline { 2 - 7 } Country & \multicolumn{2}{c}{$\begin{array}{c}\text { Gross Output } \\
\text { (Million Euro) }\end{array}$} & \multicolumn{2}{c}{$\begin{array}{c}\text { Waste Residue } \\
\text { (Tonne) }\end{array}$} & \multicolumn{2}{c}{$\begin{array}{c}\text { Greenhouse Gas } \\
\text { (Tonne) }\end{array}$} \\
\cline { 2 - 7 } & Mean & SD & Mean & SD & Mean & SD \\
\hline Netherlands & 10,853 & 835 & 698,117 & 92,351 & 908,386 & 145,953 \\
Austria & 8471 & 570 & 630,331 & 129,295 & $2,098,280$ & 251,005 \\
Poland & 10,051 & 1403 & $1,607,329$ & 303,672 & $2,140,395$ & 403,714 \\
Portugal & 4620 & 234 & 607,310 & 125,965 & $1,490,102$ & 193,030 \\
Romania & 1752 & 343 & 157,753 & 44,652 & 339,321 & 64,726 \\
Slovenia & 1093 & 43 & 180,759 & 9384 & 357,592 & 42,704 \\
Slovakia & 1678 & 55 & 338,399 & 118,181 & 173,895 & 14,960 \\
Finland & 14,004 & 1335 & $4,388,784$ & 614,598 & $3,392,642$ & 392,998 \\
Sweden & 15,504 & 1149 & $2,870,469$ & $1,906,449$ & $1,357,841$ & 348,653 \\
United Kingdom & 27,399 & 2197 & $1,762,397$ & 271,372 & $3,880,237$ & 584,932 \\
\hline
\end{tabular}

Table A3. Energy saving potential.

\begin{tabular}{|c|c|c|c|c|c|c|c|c|c|c|}
\hline \multicolumn{11}{|c|}{ Year } \\
\hline Countries & 2008 & 2009 & 2010 & 2011 & 2012 & 2013 & 2014 & 2015 & 2016 & Average \\
\hline Belgium & 5132 & 1962 & 3935 & 4325 & 5122 & 5374 & 6348 & 3355 & 3264 & 4313 \\
\hline Bulgaria & 1620 & 431 & 1240 & 0 & 0 & 0 & 316 & 1006 & 630 & 582 \\
\hline Czechia & 4785 & 2738 & 3145 & 3815 & 4821 & 4641 & 1944 & 2194 & 1564 & 3294 \\
\hline Denmark & 0 & 132 & 57 & 45 & 140 & 187 & 239 & 319 & 61 & 131 \\
\hline Germany & 33,615 & 18,211 & 10,932 & 22,357 & 36,769 & 40,495 & 45,158 & 44,483 & 29,509 & 31,281 \\
\hline Estonia & 392 & 362 & 311 & 435 & 489 & 0 & 544 & 554 & 529 & 402 \\
\hline Ireland & 0 & 0 & 0 & 0 & 0 & 0 & 0 & 0 & 0 & 0 \\
\hline Greece & 0 & 0 & 0 & 0 & 352 & 410 & 374 & 221 & 0 & 151 \\
\hline Italy & 10,168 & 1496 & 0 & 793 & 12,179 & 10,906 & 13,569 & 14,081 & 7370 & 7840 \\
\hline Latvia & 0 & 0 & 0 & 0 & 0 & 0 & 0 & 0 & 0 & 0 \\
\hline Lithuania & 0 & 0 & 0 & 0 & 0 & 0 & 0 & 0 & 0 & 0 \\
\hline Hungary & 671 & 634 & 0 & 350 & 1332 & 1460 & 1781 & 1176 & 1167 & 952 \\
\hline Netherlands & 3277 & 2309 & 0 & 290 & 2919 & 3950 & 2835 & 2516 & 434 & 2059 \\
\hline Austria & 12,736 & 6019 & 9699 & 11,531 & 12,776 & 13,927 & 14,877 & 9492 & 7906 & 10,996 \\
\hline Poland & 9018 & 6550 & 3507 & 8514 & 0 & 0 & 0 & 0 & 0 & 3066 \\
\hline Portugal & 7208 & 4351 & 2493 & 4902 & 4262 & 1277 & 0 & 0 & 0 & 2722 \\
\hline Romania & 0 & 0 & 0 & 0 & 0 & 0 & 77 & 854 & 0 & 104 \\
\hline Slovenia & 1606 & 763 & 1234 & 1313 & 1454 & 1374 & 1529 & 1327 & 1510 & 1346 \\
\hline Slovakia & 0 & 0 & 0 & 0 & 0 & 0 & 0 & 0 & 0 & 0 \\
\hline Finland & 53,564 & 41,444 & 42,858 & 44,181 & 43,904 & 33,040 & 41,791 & 38,851 & 40,283 & 42,213 \\
\hline Sweden & 40,170 & 39,931 & 33,244 & 30,126 & 32,727 & 15,354 & 21,588 & 31,215 & 31,736 & 30,677 \\
\hline \multirow[t]{2}{*}{ United Kingdom } & 8398 & 0 & 0 & 3089 & 6109 & 6140 & 7549 & 0 & 0 & 3476 \\
\hline & 8744 & 5788 & 5121 & 6185 & 7516 & 6297 & 7296 & 6893 & 5726 & \\
\hline Average & 201,102 & 133,121 & 117,776 & 142,249 & 172,871 & 144,832 & 167,817 & 158,536 & 131,687 & \\
\hline Sum & 0.552 & 0.394 & 0.329 & 0.411 & 0.506 & 0.421 & 0.523 & 0.464 & 0.383 & \\
\hline saving rate & 0 & 0 & 0 & 0 & 0 & 0 & 0 & 0 & 0 & 0 \\
\hline
\end{tabular}

Notes: (1) "saving rate" means the ratio between the energy saving potential of paper industries and actual energy consumption. (2) Significant changes in energy saving potential are due to changes in TFEE on the one hand and their own energy consumption on the other. 
Table A4. Emission reduction potential.

\begin{tabular}{|c|c|c|c|c|c|c|c|c|c|c|}
\hline \multirow{2}{*}{ Countries } & \multicolumn{9}{|c|}{ Year } & \multirow{2}{*}{ Average } \\
\hline & 2008 & 2009 & 2010 & 2011 & 2012 & 2013 & 2014 & 2015 & 2016 & \\
\hline Belgium & 551,453 & 509,644 & 665,357 & 554,526 & 555,480 & 545,426 & 633,864 & 674,205 & 672,698 & 595,850 \\
\hline Bulgaria & 62,751 & 85,317 & 9993 & 0 & 0 & 0 & 0 & 31,401 & 136,226 & 36,188 \\
\hline Czechia & 643,500 & 632,677 & 605,320 & 575,569 & 586,300 & 488,974 & 459,458 & 452,531 & 443,552 & 543,098 \\
\hline Denmark & 131,575 & 117,043 & 127,569 & 119,085 & 100,087 & 90,382 & 91,805 & 89,508 & 59,304 & 102,929 \\
\hline Germany & $8,909,735$ & $8,150,159$ & $8,278,544$ & $7,502,447$ & $7,271,315$ & $7,810,048$ & $7,709,144$ & $7,710,071$ & $6,265,023$ & $7,734,054$ \\
\hline Estonia & 33,861 & 0 & 0 & 1838 & 0 & 0 & 3811 & 6652 & 0 & 5129 \\
\hline Ireland & 0 & 0 & 0 & 0 & 0 & 0 & 0 & 0 & 0 & 0 \\
\hline Greece & 238,624 & 173,677 & 172,564 & 144,930 & 108,045 & 124,808 & 126,342 & 100,770 & 0 & 132,196 \\
\hline Italy & $5,329,307$ & $4,869,408$ & $5,828,271$ & $5,536,462$ & $5,433,395$ & $5,346,983$ & $5,051,982$ & $5,607,798$ & $4,911,341$ & $5,323,883$ \\
\hline Latvia & 0 & 0 & 0 & 0 & 0 & 0 & 0 & 0 & 0 & 0 \\
\hline Lithuania & 0 & 0 & 0 & 0 & 0 & 0 & 0 & 0 & 0 & 0 \\
\hline Hungary & 206,252 & 153,394 & 180,808 & 179,502 & 169,091 & 201,993 & 210,233 & 157,921 & 438,029 & 210,803 \\
\hline Netherlands & $1,080,318$ & 949,514 & $1,070,135$ & 989,110 & 959,880 & 870,804 & 862,835 & 680,459 & 682,150 & 905,023 \\
\hline Austria & $2,260,183$ & $2,289,374$ & $2,411,293$ & $2,358,013$ & $2,117,563$ & $2,004,328$ & $1,784,869$ & $1,884,098$ & $1,744,927$ & $2,094,961$ \\
\hline Poland & $1,460,180$ & $1,561,680$ & $1,894,079$ & $2,181,127$ & 0 & 0 & 0 & 0 & 0 & 788,563 \\
\hline Portugal & $1,106,543$ & $1,242,107$ & $1,509,692$ & $1,568,846$ & $1,525,400$ & $1,440,209$ & 0 & 0 & 0 & 932,533 \\
\hline Romania & 0 & 0 & 0 & 0 & 0 & 0 & 283,111 & 348,781 & 346,234 & 108,681 \\
\hline Slovenia & 411,494 & 391,248 & 360,445 & 328,749 & 312,511 & 303,251 & 304,219 & 288,652 & 283,029 & 331,511 \\
\hline Slovakia & 0 & 0 & 0 & 0 & 0 & 0 & 0 & 0 & 0 & 0 \\
\hline Finland & $4,119,281$ & $3,415,914$ & $3,886,194$ & $3,561,349$ & $3,193,726$ & $3,173,177$ & $3,084,347$ & $3,047,750$ & $3,014,464$ & $3,388,467$ \\
\hline Sweden & $1,918,604$ & $1,607,251$ & $1,678,737$ & $1,504,578$ & $1,386,596$ & $1,161,576$ & $1,002,398$ & 935,178 & 987,786 & $1,353,634$ \\
\hline United Kingdom & $5,138,013$ & $4,383,832$ & $3,932,540$ & $3,802,451$ & $3,802,514$ & $3,737,316$ & $3,603,171$ & 0 & 0 & $3,155,538$ \\
\hline Average & $1,527,349$ & $1,387,829$ & $1,482,343$ & $1,404,936$ & $1,250,996$ & $1,240,876$ & $1,145,981$ & $1,000,717$ & 908,398 & \\
\hline Sum & $33,601,673$ & $30,532,240$ & $32,611,540$ & $30,908,582$ & $27,521,904$ & $27,299,276$ & $25,211,590$ & $22,015,775$ & $19,984,762$ & \\
\hline Reducing rate & 0.969 & 0.972 & 0.965 & 0.969 & 0.894 & 0.885 & 0.843 & 0.729 & 0.709 & \\
\hline
\end{tabular}

Notes: "Reducing rate" means the ratio between the potential reduction of greenhouse gas emissions and actual emissions.

\section{References}

1. BP Statistical Review of World Energy. Available online: https:/ /www.bp.com/ (accessed on 15 August 2020).

2. Herring, H. Does energy efficiency save energy? The debate and its consequences. Appl. Energy 1999, 63, 209-226. [CrossRef]

3. Sari, R.; Soytas, U. Are global warming and economic growth compatible? Evidence from five OPEC countries? Appl. Energy 2009, 86, 1887-1893. [CrossRef]

4. Energy Efficiency Indicator. 2019. Available online: https:/ / www.iea.org/ (accessed on 25 November 2020).

5. CEPI: Key Statistics. 2018. Available online: https://www.cepi.org/ (accessed on 15 August 2020).

6. European Commission. Available online: https:/ / ec.europa.eu/info/index_en (accessed on 25 November 2020).

7. Patterson, M.G. What is energy efficiency? Concepts, indicators and methodological issues. Energy Policy 1996, $24,377-390$. [CrossRef]

8. Hu, J.; Wang, S. Total-factor energy efficiency of regions in China. Energy Policy 2006, 34, 3206-3217. [CrossRef]

9. Wilson, B.; Trieu, L.H.; Bowen, B. Energy efficiency trends in Australia. Energy Policy 1994, 22, 287-295. [CrossRef]

10. Boyd, G.A.; Pang, J.X. Estimating the linkage between energy efficiency and productivity. Energy Policy 2000, 28, 289-296. [CrossRef]

11. Hu, J.; Kso, C.H. Efficient energy-saving targets for APEC economies. Energy Policy 2007, 35, 373-382. [CrossRef]

12. Zhao, X.; Yang, R.; Ma, Q. China's total factor energy efficiency of provincial industrial sectors. Energy 2014, 65, 52-61.

13. Honma, S.; Hu, J. Total-factor energy efficiency of regions in Japan. Energy Policy 2008, 36, 821-833. [CrossRef]

14. Zhang, X.; Cheng, X.; Yuan, J.; Gao, X. Total-factor energy efficiency in developing countries. Energy Policy 2011, 39, 644-650. [CrossRef]

15. Mousavi-Avval, S.H.; Rafiee, S.; Jafari, A.; Mohammadi, A. Improving energy use efficiency of canola production using data envelopment analysis (DEA) approach. Energy 2011, 36, 2765-2772. [CrossRef]

16. Blomberg, J.; Henriksson, E.; Lundmark, R. Energy efficiency and policy in Swedish pulp and paper mills: A data envelopment analysis approach. Energy Policy 2012, 42, 569-579. [CrossRef]

17. Song, M.; Zhang, L.; Liu, W.; Fisher, R. Bootstrap-DEA analysis of BRICS' energy efficiency based on small sample data. Applied Energy 2013, 112, 1049-1055. [CrossRef]

18. Song, M.; Yang, L.; Wu, J.; Lv, W. Energy saving in China: Analysis on the energy efficiency via bootstrap-DEA approach. Energy Policy 2013, 57, 1-6. [CrossRef]

19. Zhou, P.; Ang, B.W. Linear programming models for measuring economy-wide energy efficiency performance. Energy Policy 2008, 36, 2911-2916. [CrossRef]

20. Yeh, T.; Chen, T.; Lai, P. A comparative study of energy utilization efficiency between Taiwan and China. Energy Policy 2010, 38, 2386-2394. [CrossRef]

21. Li, L.; Hu, J. Ecological total-factor energy efficiency of regions in China. Energy Policy 2012, 46, 216-224. [CrossRef]

22. Özkara, Y.; Atak, M. Regional total-factor energy efficiency and electricity saving potential of manufacturing industry in Turkey. Energy 2015, 93, 495-510. [CrossRef]

23. Emrouznejad, A.; Yang, G. $\mathrm{CO}_{2}$ emissions reduction of Chinese light manufacturing industries: A novel RAM-based global Malmquist-Luenberger productivity index. Energy Policy 2016, 96, 397-410. [CrossRef] 
24. Camioto, F.C.; Moralles, H.F.; Mariano, E.B.; Rebelatto, D.A.N. Energy efficiency analysis of G7 and BRICS considering total-factor structure. J. Clean. Prod. 2016, 122, 67-77. [CrossRef]

25. Choi, Y.; Zhang, N.; Zhou, P. Efficiency and abatement costs of energy-related CO2 emissions in China: A slacks-based efficiency measure. Appl. Energy 2012, 98, 198-208. [CrossRef]

26. Liu, H.; Lin, B. Incorporating energy rebound effect in technological advancement and green building construction: A case study of China. Energy Build. 2016, 129, 150-161. [CrossRef]

27. Liu, H.; Lin, B. Ecological indicators for green building construction. Ecol. Indic. 2016, 67, 68-77. [CrossRef]

28. Pérez, K.; González-Araya, M.C.; Iriarte, A. Energy and GHG emission efficiency in the Chilean manufacturing industry: Sectoral and regional analysis by DEA and Malmquist indexes. Energy Econ. 2017, 66, 290-302. [CrossRef]

29. Sahoo, N.R.; Mohapatra, P.K.J.; Sahoo, B.K.; Mahanty, B. Rationality of energy efficiency improvement targets under the PAT scheme in India-A case of thermal power plants. Energy Econ. 2017, 66, 279-289. [CrossRef]

30. Li, S.; Li, C. Modification and application of Total Factor Energy Efficiency measurement. J. Quant. Tech. Econ. $2018,9,110-125$.

31. Charnes, A.; Cooper, W.W.; Rhodes, E. Measuring the efficiency of decision making units. Eur. J. Oper. Res. 1978, 2, 429-444. [CrossRef]

32. Tone, K. A slacks-based measure of efficiency in data envelopment analysis. Eur. J. Oper. Res. 2001, 130, 498-509. [CrossRef]

33. Bhat, J.A.; Haider, S.; Kamaiah, B. Interstate energy efficiency of Indian paper industry: A slack-based non-parametric approach. Energy 2018, 161, 284-298. [CrossRef] 